\title{
PENGATURAN KECEPATAN MOTOR DC SERI BERBASIS ARDUINO UNO
}

\author{
${ }^{1}$ Diarsyah Amarullah, ${ }^{2}$ Mochammad Djaohar, ${ }^{3}$ Massus Subekti. \\ 1,2,3 Program Studi Pendidikan Teknik Elektro Fakultas Teknik Universitas Negeri Jakarta \\ 1,2,3 Email : diarsyah.af@gmail.com; djaohar@unj.ac.id; masus@unj.ac.id
}

\begin{abstract}
The purpose of this research is to design of the speed regulation of an arduino uno based seri DC motor using a DC-DC converter (Boost Converter). This research uses research and development method. The research subjects used are seri DC motor. Data analysis technique used is descriptive analysis with data collection technique that is laboratory observation using test instrument. The conclusion of this research is using a DC-DC converter or boost converter can move seri DC motor loads inertia to which has a maximum voltage of $24 \mathrm{~V}$ from the start supply to the boost converter which is $12 \mathrm{~V}$ so that the voltage increases twice. Other than that in terms of setting the DC motor speed is influenced by the amount of duty cycle controlled via by arduino uno microcontroller.
\end{abstract}

Keywords : Seri DC motors, Microcontroller Arduino Uno, DC-DC Converter (Boost Converter)

\begin{abstract}
ABSTRAK
Tujuan penelitian ini adalah untuk membuat rancang bangun pengaturan kecepatan motor DC seri berbasis arduino uno dengan menggunakan DC-DC converter (Boost Converter).

Penelitian ini menggunakan metode riset dan pengembangan. Subyek penelitian yang digunakan yaitu motor DC seri. Teknik analisis data yang digunakan yaitu analisis deskriptif dengan teknik pengumpulan data yaitu observasi laboratorium menggunakan instrumen pengujian.

Kesimpulan dari penelitian ini adalah dengan menggunakan DC-DC converter atau boost converter bisa menggerakan beban inersia pada motor DC seri yang memiliki tegangan maximal $24 \mathrm{~V}$, dari supply awal ke boost converter yaitu $12 \mathrm{~V}$ sehingga tegangan meningkat dua kali. Selain itu dalam hal pengaturan kecepatan motor DC dipengaruhi besaran duty cycle yang dikontrol melalui mikrokontroler arduino uno.

Kata kunci : Motor DC Seri, Mikrokontorller arduino uno, DC-DC Converter (Boost Converter)
\end{abstract}

\section{PENDAHULUAN}

Pada zaman modern ini ilmu pengetahuan dan teknologi yang sudah sangat cepat pertumbuhannya, sudah banyak menggunakan peralatan secara otomatis untuk membantu kerja manusia. Penemuan - penemuan teknologi sebagai penyempurnaan maupun yang baru telah dilakukan di berbagai bidang, salah satunya di bidang industri penggunaan mesin arus searah (Motor DC) banyak digunakan untuk produksi sebuah produk, contohnya conveyor yang digunakan untuk membawa produk selanjutnya diproses atau diproduksi secara cepat tanpa bantuan tenaga dari manusia.

Motor listrik memiliki sumber arus yang berebeda diantaranya ada yang sumber arus searah atau Direct Current ( DC ) dan ada juga yang sumber arus bolak-balik atau Alternating Current (AC) , motor listrik yang banyak digunakan untuk kendaraan listrik adalah motor DC. Pemilihan motor DC ini disebabkan karena kemudahan di dalam pengaturan kecepatannya (Abdul Kadir : 1984).

Dalam pemakaian daya baterai digunakan beberapa jenis konverter untuk mengubah jenis tegangan atau arus dan besar level dari tegangan atau arus sesuai dengan yang dibutuhkan (Agrawal Jai , 2001) . salah satunya adalah buckboost converter yang berfungsi mengubah level tegangan DC sebagai sumber untuk inverter, baik untuk sistem yang stand alone ataupun yang terhubung dengan grid.

Terdapat beberapa jenis konverter yang dapat digunakan, diantaranya adalah konverter ACDC, DC-DC, dan DC-AC (Agrawal jai , 2001). Pengaturan tegangan keluaran konverter dilakukan dengan cara mengatur switch yang digunakan dalam konverter sehingga mengubah besar pulsa tegangan keluaran dari konverter. Hal ini dinamakan sebagai kontrol dengan PWM (Pulse Witdh Modulation).

Penelitian melakukan percobaan untuk pengaturan kecepatan motor DC seri berbasis Arduino uno, Arduino uno berfungsi sebagai kontrol atau kendali untuk mengatur kecepatan motor DC seri sampai kecepatan motor yang diinginkan atau sesuai pada nameplate motor . Pengaturan kecepatan motor DC seri menggunakan duty cycle atau PWM (Pulse Width Modulation), pin PWM pada Arduino yang digunakan yaitu pin digital selanjutnya 
untuk mengatur lebar pulsa (duty cycle) memiliki nilai antara $0-255$. Driver untuk mengatur kecepatan motor DC menggunakan boost converter, yang memiliki kelebihan yaitu menaikan tegangan masukan terhadap tegangan keluaran yang diinginkan.

Mikrokontroller arduino merupakan salah satu board mikrokontroller yang sangat populer dan sudah diakui keunggulannya. Kemudahan dalam pemrograman, harganya yang relatife murah, software dan hardware-nya yang bersifat open source menjadikan mikrokontroller ini paling banyak digunakan di dunia.

Dengan kata lain, mikrokontroller adalah suatu alat elektronika digital yang mempunyai masukan dan keluaran serta kendali dengan program yang bisa ditulis dan dihapus secara khusus.

\section{METODE PENELITIAN}

Metode penelitian yang digunakan adalah Penelitian dan pengembangan (Research and Developmen). Penelitian ini dilakukan di Laboratorium Mesin Listrik Universitas Negeri Jakarta yang beralamat di Jl. Rawamangun Muka, Rawamangun, Jakarta Timur, 13220 adapun waktu pelaksanaan penelitian bulan Maret-Juli 2019.

Metode penelitian yang digunakan yaitu menggunakan metode penelitian dan pengembangan (Research and Development). Metode penelitian ini merupakan yang digunakan untuk menghasilkan produk tertentu, dan menguji keefektifan produk tersebut. Menurut Sujadi (2003:164) Penelitian dan Pengembangan atau Research and Development adalah suatu proses atau langkah-langkah untuk mengembangkan suatu produk baru atau menyempurnakan produk yang telah ada, yang dapat dipertanggungjawabkan.

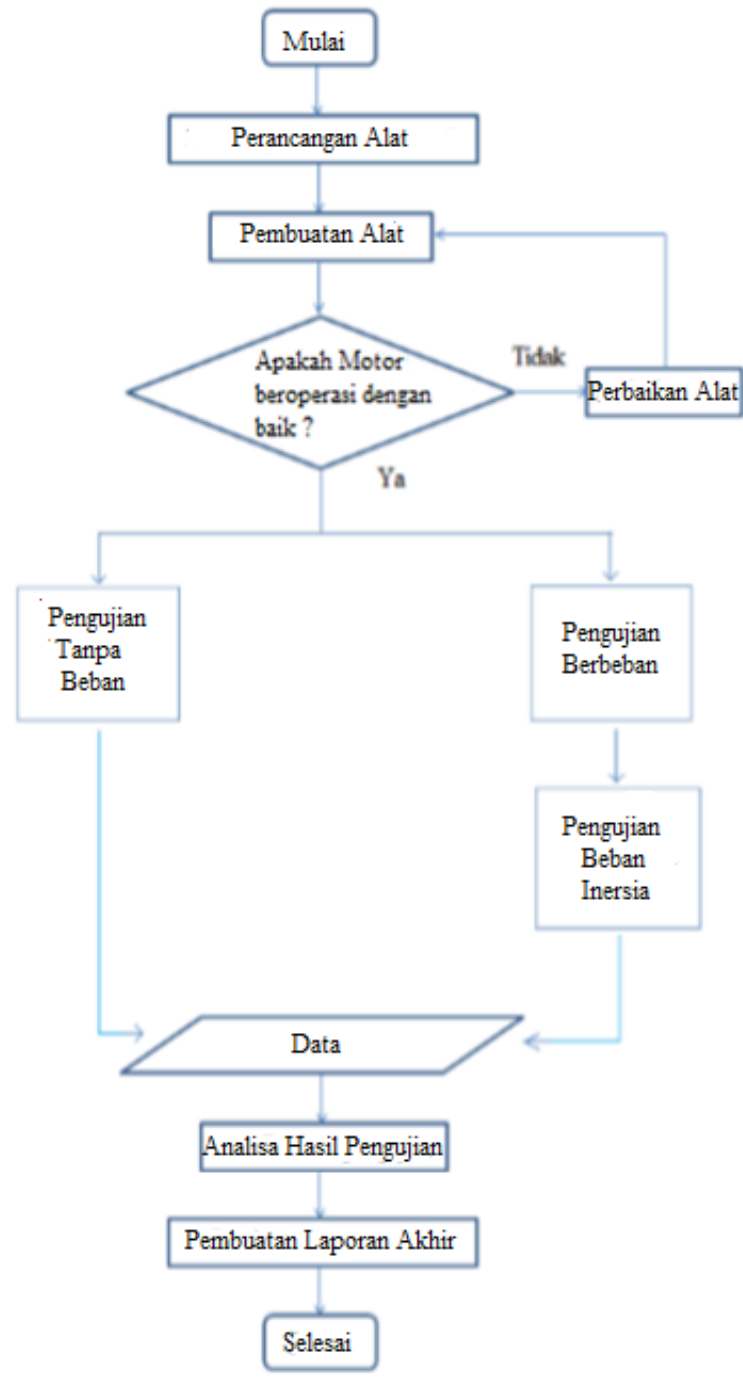

Gambar 1. Flowchart Penelitian

Teknik pengumpulan data yang digunakan pada penelitian ini yaitu observasi laboratorium. Prosedur pengumpulan data menggunakan instrumen pengujian. Teknik ini digunakan karena pengujian menggunakan dua kondisi, yaitu saat tanpa beban dan berbeban.

Teknik analisis yang digunakan yaitu analisis deskriptif dengan penarikan kesimpulan secara deskripsi menurut peneliti berdasarkan pada data-data hasil pengukuran observasi laboratorium.

\section{HASIL PENELITIAN}

Pada penelitian ini telah berhasil membuat perancangan alat pengaturan kecepatan motor DC seri berbasis arduino uno. Alat yang dikembangkan pada penelitian ini adalah menggunakan boost converter sebagai supply daya dan menggunakan sensor tegangan dan arus. Penelitian ini dilakukan di laboratorium UNJ (Universitas Negeri Jakarta) karena di 
laboratorium disana mempunya sepesifikasi motor yang akan digunakan pada penelitian ini.

Dari hasil pengolahan data, maka dapat disimpulkan bahwa alat untuk mengatur kecepatan motor DC berfungsi secara baik dan normal dengan menghasilkan tegangan, arus, dan perbedaan kecepetan putaran motor baik yang diberi beban maupun tanpa beban.

\begin{tabular}{|c|c|c|c|c|}
\hline $\begin{array}{c}\text { Teganga } \\
\mathrm{n} \\
\text { Sumber } \\
\left(\mathrm{V}_{\mathrm{S}}\right)\end{array}$ & $\begin{array}{c}\text { Duty } \\
\text { Cycl } \\
\mathrm{e} \\
(\%)\end{array}$ & $\begin{array}{c}\text { Teganga } \\
\text { n } \\
\text { Duty } \\
\text { Cycle } \\
\left(V_{D}\right)\end{array}$ & $\begin{array}{c}\text { Teganga } \\
\mathrm{n} \\
\text { Terukur } \\
\left(\mathrm{V}_{\mathrm{T}}\right)\end{array}$ & $\begin{array}{c}\text { Kecepata } \\
\text { n } \\
\text { (Rpm) }\end{array}$ \\
\hline $12 \mathrm{~V}$ & $5 \%$ & $12,6 \mathrm{~V}$ & $11,3 \mathrm{~V}$ & 660 \\
\hline $12 \mathrm{~V}$ & $10 \%$ & $13,3 \mathrm{~V}$ & $12,3 \mathrm{~V}$ & 685 \\
\hline $12 \mathrm{~V}$ & $15 \%$ & 14 & $13 \mathrm{~V}$ & 693 \\
\hline $11,7 \mathrm{~V}$ & $20 \%$ & 14,7 & $13,7 \mathrm{~V}$ & 735 \\
\hline $11,7 \mathrm{~V}$ & $25 \%$ & 15,6 & $14,4 \mathrm{~V}$ & 760 \\
\hline $11,7 \mathrm{~V}$ & $30 \%$ & 16,7 & $15,8 \mathrm{~V}$ & 835 \\
\hline $11,6 \mathrm{~V}$ & $35 \%$ & 17,8 & $16,5 \mathrm{~V}$ & 865 \\
\hline $11,6 \mathrm{~V}$ & $40 \%$ & 19,3 & $18,7 \mathrm{~V}$ & 885 \\
\hline $11,6 \mathrm{~V}$ & $45 \%$ & 21 & $19 \mathrm{~V}$ & 930 \\
\hline $11,5 \mathrm{~V}$ & $50 \%$ & 23 & $22 \mathrm{~V}$ & 970 \\
\hline
\end{tabular}

Tabel 1. Hasil Pengujian Tanpa Beban

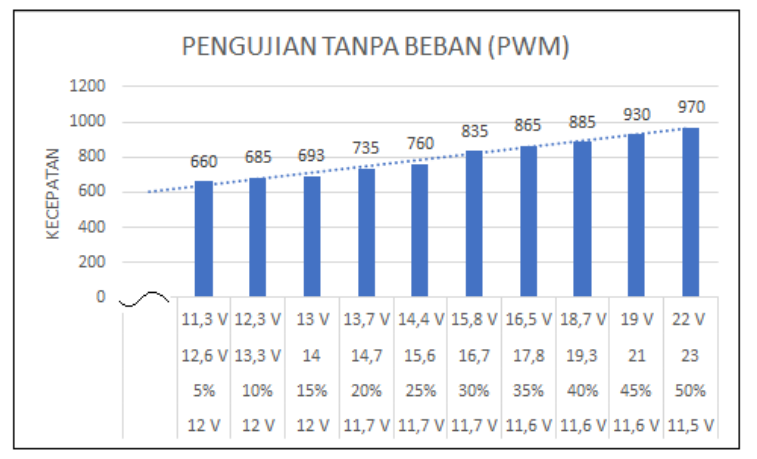

Grafik 1. Hasil Pengujian Tanpa Beban

\begin{tabular}{ccccc}
\hline $\begin{array}{c}\text { Tegangan } \\
\text { Sumber }\end{array}$ & $\begin{array}{c}\text { Duty } \\
\text { Cycle }\end{array}$ & Tegangan & $\begin{array}{c}\text { Tegangan } \\
\text { Terukur }\end{array}$ & Kecepatan \\
$\left(V_{s}\right)$ & $(\%)$ & $\begin{array}{c}\text { Duty } \\
\text { Cycle }\end{array}$ & $(\mathrm{V})$ & $(\mathrm{Rpm})$
\end{tabular}

$\left(\mathrm{V}_{\mathrm{D}}\right)$

\begin{tabular}{ccccc}
$12 \mathrm{~V}$ & $5 \%$ & $12,6 \mathrm{~V}$ & $11 \mathrm{~V}$ & 620 \\
$12 \mathrm{~V}$ & $10 \%$ & $13,3 \mathrm{~V}$ & $12 \mathrm{~V}$ & 643 \\
$12 \mathrm{~V}$ & $15 \%$ & $14 \mathrm{~V}$ & $13 \mathrm{~V}$ & 663 \\
$11,7 \mathrm{~V}$ & $20 \%$ & $14,7 \mathrm{~V}$ & $13,4 \mathrm{~V}$ & 710 \\
$11,7 \mathrm{~V}$ & $25 \%$ & $15,6 \mathrm{~V}$ & $14,8 \mathrm{~V}$ & 725 \\
$11,7 \mathrm{~V}$ & $30 \%$ & $16,7 \mathrm{~V}$ & $15,6 \mathrm{~V}$ & 733 \\
$11,6 \mathrm{~V}$ & $35 \%$ & $17,8 \mathrm{~V}$ & $16,3 \mathrm{~V}$ & 765 \\
$11,6 \mathrm{~V}$ & $40 \%$ & $19,3 \mathrm{~V}$ & $18,2 \mathrm{~V}$ & 793 \\
$11,6 \mathrm{~V}$ & $45 \%$ & $21 \mathrm{~V}$ & $20 \mathrm{~V}$ & 832 \\
$11,5 \mathrm{~V}$ & $50 \%$ & $23 \mathrm{~V}$ & $22,3 \mathrm{~V}$ & 853 \\
& & & \\
\hline Tabel 2. Hasil Pengujian Berbeban
\end{tabular}

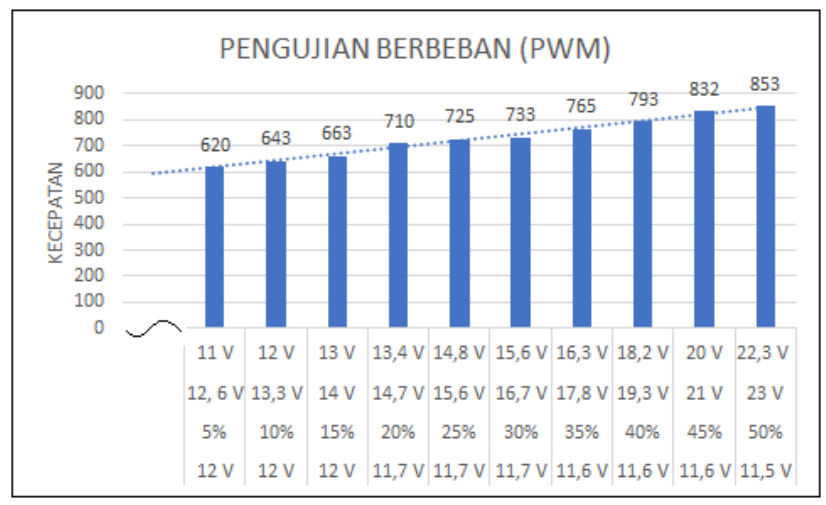

Grafik 2. Hasil Pengujian Berbeban

\section{KESIMPULAN}

Pada penelitian ini berhasil membuat perancangan alat mengatur kecepatan motor DC seri berbasis arduino yang tanpa beban dan berbeban

Motor DC seri yang tanpa beban dan berbeban, berpengaruh pada besar duty cycle terhadap putaran kecepatan motor DC seri.

Batasan tegangan dan lebar pulsa (duty cycle) yang dihasilkan boost converter berbanding lurus dengan kecepatan motor DC seri.

\section{DAFTAR PUSTAKA}

Ashari, M. (2017). Desain Konverter Elektronika Daya. Ed ke-1. Bandung: Informatika 
Anonimous. (2011). PWM (Pulse Width Modulation). http://digilib.ittelkom.ac.id. Diakses tanggal 29 November 2012

Chattopadhyay, D., Rakhsit, P.C., Saha, B., Purkait, N.N. (1989). Dasar Elektronika. Terjemahan oleh Sutanto. Jakarta; UI Press

Kadir, A. (2016). Simulasi Arduino. Ed ke-1. Jakarta: Elex Media Komputindo

Kadir, A. (1984). Mesin Arus Searah. Ed ke-2. [tempat tidak diketahui]

Malvino, P.A. (2004). Prinsip-prinsip Elektronika. Terjemahan oleh Santoso, J.A. Ed ke-1. Jakarta: Salemba Teknika

Rashid, M. (2001). Power Electronics. United Kingdom: Academic Press

Syahwil, M. (2013). Mikrokontroller Arduino. Ed ke-1. Yogyakarta: Andi Offset

Sugiyono. (2011). Metode Penelitian Kuantitatif, Kualitatif dan $R \& D$. Bandung: Alfabeta 